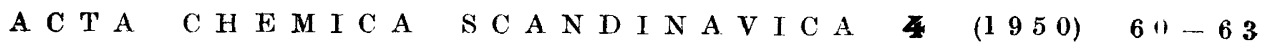

\title{
The Synthesis of the Monochloro Methoxyquinols and some Related Substances
}

\author{
LEN NART ASP and BENGT LINDBERG
}

Organisk-kemiska Institutionen, Kungl. Tekniska Högskolan, Stockhoỉm, Sweden

\begin{abstract}
Q
uinones generally react with hydrogen chloride with the formation of monochloro quinols, which are rather stable compounds. By addition of hydrogen chloride to 4,4'-dimethoxydiquinone, however, Erdtman ${ }^{1}$ obtained a substance (I), which possessed unexpected properties. On attempted recrystallization, it decomposed into hydrogen chloride and the original quinone. Contrary to expectation, this compound on acetylation yielded a diacetate, not a tetraacetate.
\end{abstract}<smiles>COC1CC(O)C(C2C(O)CC(OC)C(O)C2Cl)C(O)C1O</smiles>

I ?

Since the structure of this peculiar addition product remains unelucidated, this problem deserves reinvestigation. To begin with, the three monochloro methoxyquinols have been synthesized* in order to compare the ultra-violet absorption of their actates with that of the acetate of the 'chlorophenol' (I).

The monochloro methoxyquinols were prepared by Dakin oxidation ${ }^{2}$ of the corresponding monochloro vanillins. The chloromethoxyquinols were easily oxidized to the corresponding quinones with ferric chloride. Under

\footnotetext{
* According to private information from Dr. G. Castelfranchi similar reactions have been independentsy accomplished by A. Oliverio and G. Castelfranchi, Rome. This work will be published shortly in Gazz. Chim. Ital.
} 
the same conditions methoxyquinol yields a diphenyl derivative ${ }^{1}$. The various substances prepared and their melting points are listed in Table 1.

Table 1. Melting points * of the compounds described in this communication.

\begin{tabular}{|l|c|c|c|}
\hline \multicolumn{1}{|c|}{ Type of substance } & $\begin{array}{c}\text { 2-Methoxy- } \\
-3 \text {-chloro }\end{array}$ & $\begin{array}{c}\text { 2-Methoxy- } \\
-5 \text {-chloro }\end{array}$ & $\begin{array}{c}\text { 2-Methoxy- } \\
-6 \text {-chloro }\end{array}$ \\
\hline & $107-108$ & $128-129$ & $138-139$ \\
Quinol & $80.5-81$ & $125-126$ & $80.5-81$ \\
Quinol diacetate & $75-76$ & $169-170$ & $156.5-157$ \\
Quinone & &
\end{tabular}

The results of the ultra-violet absorption measurements and further investigations of the 'chlorophenol' (I) will be published later.

\section{EXPERIMENTAL}

The three monochloro vanillins were prepared according to Raiford and Lichty ${ }^{3}$.

$$
\text { 2-M e thoxy-3-c hlor o quinol }
$$

2-Chlorovanillin (2.5 g) was dissolved in $4 \%$ sodium hydroxide $(20 \mathrm{ml})$, and hydrogen peroxide $(2.5 \mathrm{ml} 30 \%$ hydrogen peroxide in $20 \mathrm{ml}$ water) was added. The temperature increased and the solution turned brown. After 15 minutes the solution was neutralized with concentrated hydrochloric acid and extracted continuously with ether over night. The ether solution was dried over calcium chloride and concentrated. The crystalline residue (1.75 g) was recrystallized from water. Two recrystallizations yielded the pure, colorless substances M. p. $107-108^{\circ}$.

$$
\mathrm{C}_{7} \mathrm{H}_{7} \mathrm{O}_{3} \mathrm{Cl}(174.6) \quad \text { Calc. } \mathrm{OCH}_{3} \quad 17.8 \quad \text { Found } \mathrm{OCH}_{3} \quad \text { 17.5 }
$$

\section{2-M ethoxy-3-chloroquinol diacetate}

2-Chlorovanillin was oxidized as above, and then additional $4 \%$ sodium hydroxide $(20 \mathrm{ml})$ was added to the solution. This alkaline solution was shaken for 10 minutes with acetic anhydride $(5 \mathrm{ml})$. The mixture was extracted with ether $(2 \times 50 \mathrm{ml})$ and the ether solution washed with dilute sodium carbonate and water, dried over calcium chloride and concentrated. The resulting oil $(2.6 \mathrm{~g})$ slowly crystallized and the crude product was recrystallized from methanol. Three recrystallizations yielded the pure colorless substance M. p. $80.5-81^{\circ}$.

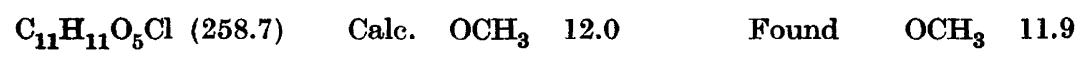

* All melting points uncorrected. 


\section{2-Methoxy-3-chlor oquinone}

2-Chlorovanillin $(2.5 \mathrm{~g})$ was oxidized as above, and the solution acidified with concentrated hydrochloric acid $(5 \mathrm{ml})$. Ferric chloride hexahydrate $(4 \mathrm{~g}$ dissolved in a small amount of water) was added. The yellow quinone immediately precipitated and was collected by filtration. Yield $2.0 \mathrm{~g}$. 'Two recrystallizations from ligroin yielded the pure substance, which crystallized in yellow needles. M. p. $75-76^{\circ}$.

$$
\mathrm{C}_{7} \mathrm{H}_{5} \mathrm{O}_{3} \mathrm{Cl}(172.6) \quad \text { Calc. } \quad \mathrm{OCH}_{3} \quad 18.0 \quad \text { Found } \mathrm{OCH}_{3} \quad 17.7
$$

Reductive acetylation with zinc dust and acetic anhydride yielded 2-methoxy-3chloroquinol diacetate, identical with the substance described above.

$$
\text { 2-M e th o x y-5-chlor o quinol }
$$

This substance was prepared in the same way as the 3 -chloro derivative, $2.5 \mathrm{~g} 6$-chlorovanillin yielded $2.0 \mathrm{~g}$ crude 2-methoxy-5-chloroquinol. Two recrystallizations from ethanol yielded the pure, colorless substance. M. p. $128-129^{\circ}$.

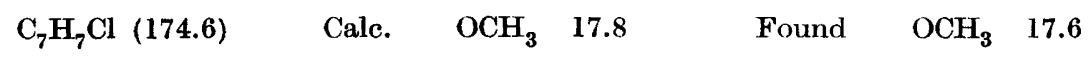

2-Methoxy-5-chloroquinol diacetate

This substance was prepared in the same way as the 3-chloro derivative. $2.5 \mathrm{~g} \mathrm{6}$ chlorovanillin yielded $2.6 \mathrm{~g}$ crude 2-methoxy-5-chloroquinol diacetate. Two recrystallizations from methanol yielded the pure, colorless substance. M. p. 125-126.

$$
\mathrm{C}_{11} \mathrm{H}_{11} \mathrm{O}_{5} \mathrm{Cl}(258.7) \quad \text { Calc. } \quad \mathrm{OCH}_{3} \quad 12.0 \quad \text { Found } \mathrm{OCH}_{3} \quad 12.0
$$

$$
\text { 2-M e thox y-5-ch lor o quinone }
$$

This substance was prepared in the same way as the 3-chloro derivative. $2.5 \mathrm{~g} 6$ chlorovanillin yielded $2.0 \mathrm{~g}$ of the crude 2 -methoxy-5-chloroquinone. Two recrystallization from ethanol yielded the pure substance in the form of yellow needles. M. p. 169 $-170^{\circ}$.

$$
\mathrm{C}_{7} \mathrm{H}_{5} \mathrm{OCl}_{3} \text { (172.6) } \quad \text { Calc. } \quad \mathrm{OCH}_{3} \quad 18.0 \quad \text { Found } \quad \mathrm{OCH}_{3} \quad 17.9
$$

Reductive acetylation with zinc dust and acetic anhydride yielded the 2-methoxy-5chloroquinol diacetate described above.

\section{2-M thoxy-6-chlor oquinol}

This substance was prepared in the same way as the 3-chloro derivative. $2.5 \mathrm{~g} \mathrm{5}$ chlorovanillin yielded $2.1 \mathrm{~g}$ crude 2-methoxy-6-chloroquinol. Two recrystallizations from benzene yielded the pure, colorless substance. M. p. $138-139^{\circ}$.

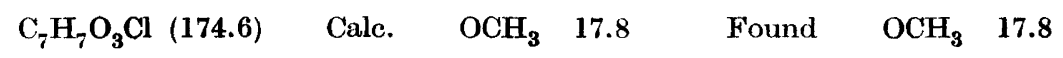


2- Methoxy-6-chloroquinol diacetate

This substance was prepared in the same way as the 3-chloro derivative. $2.5 \mathrm{~g} 5$ chlorovanillin yielded 2.7 crude 2 -methoxy-6-chloroquinol diacetate. Two recrystallizations from methanol yielded the pure, colorless substance. M. p. $80.5-81^{\circ}$.

$$
\mathrm{C}_{11} \mathrm{H}_{11} \mathrm{O}_{5} \mathrm{Cl}(258.7) \quad \text { Calc. } \mathrm{OCH}_{3} \quad 12.0 \quad \text { Found } \mathrm{OCH}_{3} \quad 12.0
$$

2-Methoxy-6-chlor oquinone

This substance was prepared in the same way as the 3-chloro derivative. $2.5 \mathrm{~g} 5$ chlorovanillin yielded $1.8 \mathrm{~g}$ crude 2-methoxy-6-chloroquinone. Two recrystallizations from ethanol yielded the pure substance in orange-red needles. M. p. 156.5-157 .

$$
\mathrm{C}_{7} \mathrm{H}_{5} \mathrm{O}_{3} \mathrm{Cl}{ }^{\prime}(172.6) \quad \text { Calc. } \quad \mathrm{OCH}_{3} \quad 18.0 \quad \text { Found } \mathrm{OCH}_{3} \quad 18.1
$$

Reductive acetylation with zinc dust and acetic anhydride yielded the 2-methoxy-5chloroquinol diacetate described above.

\section{SUMMARY}

The three isomeric quinols, quinol diacetates and quinones with one chlorine and one methoxyl group have been prepared.

We are indebted to Professor H. Erdtman for suggesting this work.

\section{REFERENCES}

1. Erdtman, H. Proc. Roy. Soc. A 143 (1933) 191.

2. Dakin, H. P. Am. Chem. J. 42 (1909) 492.

3. Raiford, L. C. and Lichty, J. G. J. Am. Chem. Soc. 52 (1930) 9576.

Received November 23, 1949. 